\title{
Óscar Martín Centeno, poeta digital visto por sí mismo
}

\author{
Óscar Martín Centeno ${ }^{1}$ \\ Licenciado en Historia y Ciencias de la Música \\ oscarmartincenteno@gmail.com
}

Palabras-clave: poesía, digital, multimedia, animación, tipografía, cinética, videopoesía, performance, videoarte.

\section{Introducción}

Si queremos darle a la poética multimedia una entidad propia, debemos centrarnos especialmente en las cuestiones que pueden hacer de ella una nueva disciplina. Esto implica asumir la existencia de un lenguaje específico, que desarrollando los códigos propios de cada una de las expresiones artísticas que híbrida, sea capaz de ofrecer algo más que la simple suma de las mismas sobre una base literaria.

Para conseguir esto debe existir una voluntad creadora plenamente dirigida y una coherencia en los resultados obtenidos. Sólo de esta manera será posible que cada una de las piezas impregne a las demás, hasta hacerlas necesarias para mantener la emoción del conjunto. Esta forma de entender la propuesta exige un planteamiento donde los diferentes lenguajes artísticos se fundan, en busca de una obra capaz de impregnar todos los sentidos del espectador. Por eso, el poeta multimedia debe conocer, comprender y adentrarse en las diferentes disciplinas. Debe entender sus códigos, para, posteriormente, construir la forma en que sus respectivas características se complementarán en busca de la obra completa.

\footnotetext{
${ }^{1}$ www.oscarmartincenteno.com 


\section{Tradición y modernidad}

Las nuevas tecnologías presentan un marco absolutamente nuevo, tanto para la lectura como para la representación poética, pero, curiosamente, todas estas nuevas herramientas acercan la poesía a su expresión primigenia, a la voluntad oral que presidía el latido original de los versos. De nuevo se hace primordial la efectividad orgánica del sonido, de nuevo importa la puesta en escena, la presencia visual que da cuerpo al texto. Todos esos elementos, postergados en el libro, tienen de repente un campo para devolver a la poesía una expresión poderosa, que conmueve con todo el artificio que facilitan los nuevos medios. Lo que hacemos, por tanto, al utilizar estas posibilidades, no es otra cosa que recuperar todo un ámbito expresivo: el ámbito de la oralidad, que se revitaliza, refuerza y reinventa mediante el uso de la tecnología. No es ningún secreto que, al hacerlo, también abrimos nuevas direcciones, explorando distintos cauces para la expresión de la cultura.

Todos los recursos que inciden en la naturaleza sonora del verso son ampliamente utilizados en la poesía multimedia, pero también son usados en otra serie de propuestas, como las presentaciones de spoken word, polipoesía, perfopoesía y slam poetry. Esta serie de fórmulas para presentar la poesía buscan, sobre todo, darle una dimensión escénica, mostrarla al espectador. Sin embargo, con la salvedad de la poesía multimedia, ninguna ofrece un cauce distinto del que se había usado hasta ahora. Muchos poetas han utilizado música para acompañarse e incluso complejas escenificaciones teatrales. También se han usado los nuevos medios, pero sin presentar una voluntad de integración real. Aquí está el quid de la cuestión, la premisa que hace de la poesía multimedia una nueva forma de entender el hecho poético, porque crea una arquitectura donde cada viga es fundamental para la pervivencia del edificio.

\section{Integrar lenguajes o acompañar los versos}


Por eso, la cuestión fundamental que puede separar la poesía multimedia de otra serie de manifestaciones artísticas relacionadas con la literatura, es la voluntad explícita de crear una sinergia expresiva aunando diferentes disciplinas. Siguiendo esta idea, en mi propia forma de trabajar, los textos, la música y el lenguaje visual, están totalmente interconectados. No significa que sigan unas vías estrictamente paralelas, pero si existe una simbiosis constante entre los diferentes elementos mientras se van creando. Voy componiendo la música de acuerdo con el desarrollo del poema, e intento que ese mismo texto esté estructurado de forma que integre perfectamente la idea musical. Las escenas visuales son también montadas junto con los versos y, en algunos casos, pueden incidir en el planteamiento del texto. Esto sucede, especialmente, cuando trabajo sobre tipografía cinética, que exige un tratamiento en pantalla lo suficientemente dinámico como para evitar determinadas estructuras métricas. Toda esta reflexión formal influye bastante en el proceso de escritura: el autor establece una constante indagación, que, en muchos casos, se traduce en un interés por aumentar la concisión, la exactitud y el uso efectivo de todos los recursos literarios. Este proceso tiene una gran influencia en la creación, al plantear una continua investigación sobre la naturaleza del lenguaje poético. De esta forma, podemos afirmar que no sólo se produce una integración efectiva entre diferentes ámbitos expresivos, sino que el propio proceso creativo impulsa una reflexión constante sobre las posibilidades de los diferentes lenguajes artísticos.

Es fundamental establecer una diferenciación entre este planteamiento y el simple acompañamiento de los versos por otras disciplinas. En esa forma de trabajar no se plantea ninguna sinergia, ni ningún tipo de integración artística. Obviamente, no estamos hablando del mismo proceso, del mismo objetivo, ni del mismo resultado final. Es importante marcar esta diferencia, porque en ese caso no podríamos hablar de una nueva forma expresiva, sino simplemente de un acompañamiento para los poemas.

\section{El artista total o el monstruo de tres cabezas}


Una de las cuestiones fundamentales a la hora de plantear un proceso creativo donde confluyen diversos lenguajes expresivos, es la disyuntiva ante diversas opciones de trabajo. Un único creador puede desarrollar todos los elementos de la obra, se pueden establecer colaboraciones con otras personas, o se puede montar un equipo estable para llevar a cabo el proyecto.

Estas tres opciones son la más usadas a la hora de desarrollar una propuesta multimedia, y es especialmente destacable el hecho de que, dependiendo de la fórmula elegida, el resultado suele ser muy diferente.

Quizá la menos recomendable es la opción de las colaboraciones. Si nuestro objetivo es conseguir una obra muy cohesionada, necesitaremos una fórmula de trabajo que permita integrar de forma fluida todos los elementos. Eso es particularmente difícil cuando se procura hacer una buena creación en los diferentes ámbitos, pero sin un planteamiento previo donde se aúnen criterios de manera clara. Otra limitación importante es el hecho de que, si los diferentes creadores desconocen el lenguaje que utilizan los demás, es imposible que haya un diálogo profundo, debido tanto a las limitaciones que impone la técnica multimedia, como a la naturaleza que conlleva cada trabajo artístico. Es imposible que haya una comunicación plena entre el poeta y el músico si ambos desconocen el lenguaje del otro, de la misma forma que es muy difícil establecer un diálogo pleno entre el autor y el animador audiovisual si el poeta no entiende las posibilidades, limitaciones y recursos que conlleva la creación multimedia.

La opción de organizar un grupo muy cohesionado, donde además haya un conocimiento importante, a nivel individual, de los diferentes lenguajes artísticos, nos ofrece dos ventajas frente a la opción anterior. En primer lugar habrá una comprensión de las diferentes disciplinas, lo que permitirá una comunicación mucho más fluida. En segundo lugar, si se mantiene esa comunicación constante, será posible establecer la creación de un producto único, en lugar de una suma de aportaciones. Esto sólo se puede conseguir si realmente hay una intención clara de dejar atrás cualquier tipo de intervención personalista para desarrollar 
un activo trabajo grupal. Evidentemente habrá también dificultades, especialmente si existen diferentes puntos de vista con respecto a la obra, pero sin duda se logrará un diálogo creativo mucho más fluido que en la opción anterior.

Y llegamos a la opción que yo juzgaría más recomendable: que un mismo autor se haga cargo de los diferentes lenguajes artísticos. En este caso concreto el poeta desarrollaría la escritura de los versos, así como el ámbito sonoro y visual. Aunque lo primero que nos puede venir a la cabeza es la dificultad que conlleva esta propuesta, debemos tener en cuenta que la técnica nos permite la creación de ambientaciones sonoras sin conocimientos de música, al igual que la creación audiovisual sin amplios conocimientos de animación 3D o edición de vídeo. Es decir, estamos hablando de primar una cuestión sobre otra: primar la integración artística sobre la calidad individual de los distintos elementos. Podemos tener una buena pieza de videoarte o una buena música que distraiga del texto, o podemos construir una obra completa donde cada uno de los planos se integre de una forma clara con los demás.Precisamente, para conseguir este objetivo, es recomendable que el poeta multimedia se atreva a experimentar con distintas disciplinas, porque de esta forma la creación literaria no se verá perjudicada, sino que se enriquecerá constantemente al entrar en contacto con nuevas formas de expresión.

Esta es la opción que yo he tomado como poeta multimedia y estoy convencido de que es la forma de lograr el objetivo que me he marcado: la creación de una obra que, aprovechando los avances de nuestra época, lleve la expresión poética a una puesta en escena donde se recuperen los principios orgánicos de la oralidad, la conexión con el público, y la voluntad de abrir nuevos caminos expresivos.

\section{La importancia del texto. Tipografía en movimiento}

Cuando se trabaja sobre géneros híbridos es importante saber cuáles son las características diferenciadoras, las cuestiones que dan suficiente entidad a una propuesta como para hacer 
de ella una fórmula sólida. En el caso de la poética multimedia es evidente que existen una serie de similitudes con otros géneros. El videoarte sería quizá el más cercano. La gran diferencia está en la base de la propuesta. Si hablamos de poesía multimedia planteamos una definición que necesariamente debe tener en la literatura, en el texto, su motor fundamental. De otra forma tendríamos una propuesta de videoarte con pinceladas poéticas, no una iniciativa donde la fuerza del texto, la calidad del mismo, se ve reforzada por una sinergia de disciplinas artísticas. Hay muchos "videopoemas" donde nos encontramos una recreación audiovisual de un texto. Esto no deja de ser videoarte también, ya que no desarrollamos las visuales y la música conjuntamente con el poema, sino que estamos creando una versión en otros ámbitos expresivos de un trabajo previo.

Alejada de estas propuestas, la poesía multimedia puede alimentarse de procesos de animación de texto, fusiones entre imágenes de vídeo, iniciativas de color, forma y ritmo sobre la creación poética. Estas posibilidades tienen, además, una clara influencia literaria, estando muy relacionadas con las propuestas de las vanguardias históricas. Al trabajar de forma gráfica sobre un texto se introducen toda una serie de intenciones estéticas que influyen en cómo percibimos el mensaje que transmiten las palabras. De esta forma recuperamos un rico campo de expresión, que tiene, como digo, unas claras raíces en el futurismo, el dadaísmo y el surrealismo. La tipografía, el color y el diseño vuelven a ser importantes, pero con varias diferencias. El texto ya no se mueve aparentemente en un único plano. La ilusión de perspectiva que introduce la animación 3D nos permite jugar con complejas formas geométricas, incluso con la superposición de palabras sobre vídeo, creando la ilusión de que se encuentran en el mismo plano que algún elemento concreto de la imagen. Este tipo de posibilidades, animadas en tres dimensiones, nos permiten llevar las propuestas de las vanguardias históricas a un ámbito que habría sido absolutamente inimaginable.

Sin embargo, para que podamos ofrecer algo más que una actualización de las propuestas existentes, tenemos que promover otra intención expresiva. Los propios medios que utilizamos nos pueden dar la respuesta. A la dimensión espacial hay que unir ahora la 
dimensión temporal, y también la velocidad, las características cinéticas de los elementos textuales. Esto tiene toda una serie de implicaciones que cambian por completo nuestra forma de percibir la literatura con respecto al libro. Ha cambiado el tempo, la forma, el ritmo. $Y$ ha cambiado la manera en que la literatura nos conduce en su girar de emociones.

\section{Tiempo y espacio en el mundo multimedia}

La primera diferencia notable es que el tiempo ya no lo marca el lector. Junto con la disposición de los elementos en la pantalla hay un ritmo concreto. En esta percepción, casi musical, de la presentación literaria, tenemos también un nuevo acercamiento a la oralidad. Porque en la oralidad es fundamental el tiempo, y en este tipo de propuestas, donde se recupera el carácter oral de la literatura, todos los elementos que lo forman deben estar absolutamente sincronizados.

Además son fundamentales el movimiento, el tipo de movimiento y la velocidad del mismo. Al crear un poema multimedia estas acciones poseen una intención concreta, igual que también la tienen los colores, las tipografías o las texturas utilizadas. El movimiento adquiere significado, crea sensaciones y establece un ánimo concreto, por lo que resulta fundamental trabajar en este campo. Debemos tener en cuenta, al trabajar con tipografía cinética, que la velocidad de las versos en la pantalla es independiente de la velocidad del recitado, y precisamente por eso podemos jugar con toda una serie de contrastes que sirvan para poner de relieve la agitación interior. Si queremos mover unas palabras en la pantalla mientras se produce la declamación, dependiendo de las dimensiones de la tipografía, podremos moverlas lentamente o a una velocidad vertiginosa. No es lo mismo hacer aparecer una frase mientras la recitamos o hacer aparecer cada palabra, cada sílaba o cada letra. La velocidad visual sería mucho mayor. Un verso recitado lentamente puede expresar, de esta forma, el temblor interior del poema mediante su rápida proyección silábica.

También hay cuestiones diferenciadoras relacionadas con el espacio, algunas tienen que ver con la simple proyección del trabajo. Cuando recito siempre considero la escena un elemento 
esencial, y por escena no entiendo únicamente la presencia del poeta, sino, sobre todo, la comunicación que se produce entre el artificio tecnológico y el propio poeta. Por esa razón al proyectar visuales no siempre estamos hablando del ámbito de una pantalla de proyección, porque podemos hacerlo sobre nosotros mismos (de manera que formaríamos parte de la proyección), sobre el público, o sobre cualquier elemento que genere un movimiento aún mayor. He realizado recitales y proyecciones multimedia sobre montajes con telas semitransparentes, que oscilaban al usar diversos ventiladores. Podían ser movidos o agitados en directo, y, de esta forma, daban al espectáculo una mayor interacción entre proyección y escena. Viendo estas posibilidades de trabajo, cercanas a la instalación artística, nos podemos plantear que ya no es la página, pero tampoco la pantalla del ordenador, el único lugar donde se pueden encontrar las palabras. El poeta multimedia juega con todas las posibilidades y un edificio, una muralla o un juego de espejos pueden ser lugares donde fluya el texto poético.

La otra diferencia, con respecto al espacio, tiene que ver con la fugacidad. Antes, las palabras permanecían en la página. Ahora no. Esta cuestión está relacionada con la idea de lo efímero. El arte multimedia, al ocurrir en el tiempo, se aleja de la naturaleza inmutable del libro. El espacio es variable, cambiante y etéreo. Todos los elementos que forman parte del baile deben ser percibidos por el espectador en un momento concreto. Fuera de ese momento el artificio poético desaparece.

\section{La sala de máquinas}

\section{Proceso creativo en marcha}

El trabajo creativo del poeta multimedia se desenvuelve en varios campos y en la mayor parte de las ocasiones lo hace, además, de forma simultánea. Por esta razón, el proceso es bastante más complejo que el habitual en literatura. En mi caso concreto, compongo la música de una forma prácticamente simultánea a la elaboración de los versos, para que el poema y la creación sonora puedan adaptarse de forma adecuada. Sin esa integración sería 
imposible sincronizar toda la parte de animación. Por eso, aunque vaya desarrollando la creación visual de forma paralela, es importante que la base de sonido sea clara, tenga una estructura definida y me permita después utilizar ese guión para cada una de la secciones visuales.

Una vez que el proceso sonoro ha avanzado lo suficiente, y antes de que esté concluido, hago todos los bocetos de las animaciones. De esta forma, tanto la estructura como los cambios de textura en la música, tendrán una proyección clara desde el punto de vista visual. Si esto no se hiciera antes de que todo el trabajo musical estuviera concluido, podríamos tener serias dificultades a la hora de desarrollar cualquier idea, ya que las propias visuales provocarán la necesidad de realizar adaptaciones tanto en la literatura como en la música. Al trabajar sobre la materia prima previamente al montaje final, será posible cambiar versos, hacer modificaciones musicales, e incluso realizar transformaciones en el desarrollo de la obra. Esta cuestión, que puede parecer una intervención externa en la base poética, no sólo no influye negativamente, sino que abre, como ya he comentado, un proceso de reflexión sobre el texto. De esta forma, el poema se continúa trabajando, lo que mejora su expresión sonora, su concreción, así como la eliminación de todo lo que no es esencial para su funcionamiento.

El trabajo sobre los versos atendiendo a este tipo de cuestiones acerca todavía más la poesía a su expresión oral, logrando una sonoridad que no siempre se consigue cuando se trabaja el texto exclusivamente sobre el papel. De la misma forma, la continua reflexión sobre la estructura musical, las texturas que acompañan a los versos y su desarrollo melódico, armónico y percusivo, nos lleva a una evolución musical equivalente. Cambios de tonalidad, cambios tímbricos, de tempo y de estructura aparecen de forma fluida al obligarnos a plantear una integración donde ganan todos sus elementos.

\section{La parte técnica}


Siempre he pensado que, a la hora de utilizar la tecnología, debemos hacer todo lo posible por eliminar las barreras existentes entre el interface y el creador. Esto sólo se consigue cuando hay un conocimiento profundo y fluido de las herramientas que se utilizan. De la misma forma que un poeta no piensa en la realización de las letras a la hora de escribir un poema, un artista multimedia tampoco puede coartar su creatividad por las dudas de funcionamiento de los programas utilizados. Si esto ocurriera pondríamos más atención en el propio proceso técnico que en la creación artística, lo que supondría un problema añadido que debemos evitar.

\section{Trabajo sonoro}

Para trabajar en el campo sonoro existen multitud de posibilidades. Personalmente hago el boceto sonoro con un instrumento (piano), para posteriormente desarrollar la idea, la instrumentación y los arreglos sobre el ordenador. Se pueden utilizar multitud de programas y lo más conveniente es probar varios, ver cual se aproxima más a nuestra forma de trabajo y aprender su uso hasta que nos olvidemos realmente de que está ahí. Además de este programa (que hará las bases de secuenciador, a menos que queramos utilizar un secuenciador dedicado) podremos usar también sintetizadores, samplers y unidades de efectos. Dependerá de nuestros conocimientos musicales, así como del concepto que queramos desarrollar con las texturas sonoras.

\section{Trabajo visual}

En el campo visual tenemos también una gran cantidad de posibilidades. Dependiendo de nuestro objetivo utilizaremos más el vídeo o la animación. El problema que puede tener el vídeo es, como ya he comentado más arriba, que en lugar de hacer algo que realmente se integre con el poema, podemos acabar realizando una versión en vídeo del mismo. La animación suele posibilitar mejores resultados en este aspecto, pero un buen montaje de vídeo también puede dar lugar a trabajos realmente hermosos. Personalmente utilizo los dos campos. En animación uso un programa de animación 3D con el que desarrollo las texturas, 
la animación de tipografía cinética y el movimiento de todos los objetos en el espacio. Este trabajo, que suele ser el más laborioso, es el que nos permite realizar una integración visual más efectiva con la declamación, posibilitando la aparición de palabras, texturas y objetos en sincronía con el recitado en directo. El montaje de vídeo lo realizo con un programa de edición de vídeo, que permite también realizar los recortes necesarios, así como utilizar filtros, efectos y todo tipo de retoques sobre el material original. Posteriormente vuelvo a pasar el vídeo por el programa de animación para mezclarlo con todas las animaciones y darle movimiento si es necesario. El trabajo final se monta directamente de nuevo sobre el programa de edición de vídeo. Aquí es posible exportar después diversas pistas con distintos elementos por si queremos hacer combinaciones en directo con una mesa de mezclas de vídeo.

\section{Mis recitales de poesía multimedia}

Cuando alguien asiste por primera vez a un recital de poesía multimedia la duda generalizada es si lo que acaba de ver puede llamarse recital de poesía. Vemos la literatura como algo tan serio, tan anquilosado, que nos parece extraño empezar a sentirlo actual, moderno, vivo. Simultáneamente las personas que jamás se habrían acercado a un recital empiezan a interesarse por esas nuevas posibilidades. Hay espectadores que lo ven como un concierto de 


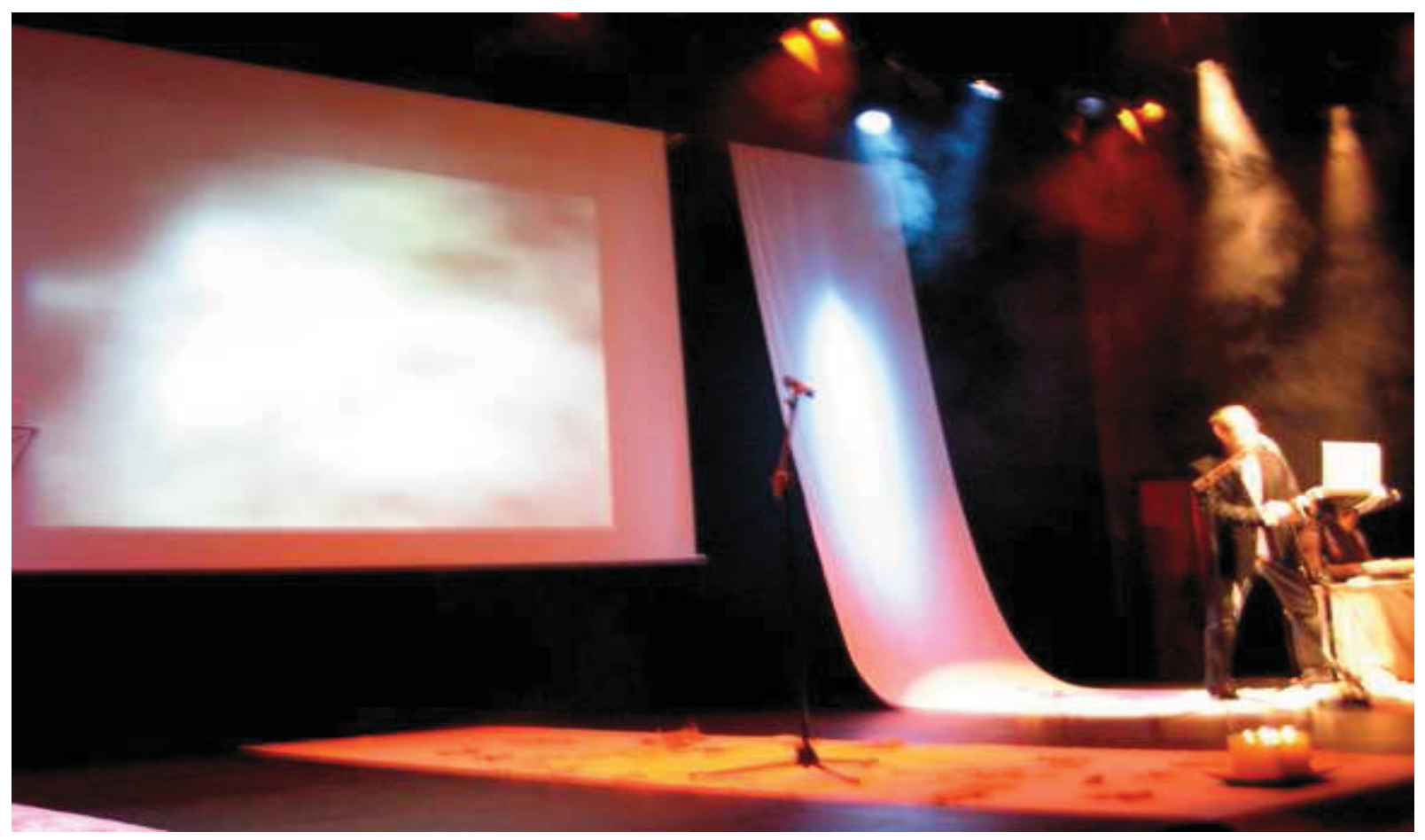

música, otros que lo disfrutan como una creación de videoarte. La mayor parte de esos asistentes tendrán diferentes referencias artísticas, en algunos casos muy alejadas de la literatura, pero también acaban percibiendo que los poemas son la base que desarrolla la creación completa. La llave para entrar en esa inmensa sala de magia.

El recital multimedia es la presentación de la obra total. Es la puesta en escena donde todas las disciplinas artísticas en las que he estado trabajando confluyen. Para mí es el momento en que los poemas quedan realizados, ya que sin esa presencia física del poeta faltaría la principal fuerza expresiva. Para el espectador se trata de una experiencia donde ven al poeta en escena, recitando, coordinando las bases sonoras y los planos visuales y tocando en directo algunos instrumentos. La interacción que se produce con los espectadores en ese momento es fundamental, ya que, al igual que en un concierto de música, el propio espectáculo se va adaptando a las sensaciones que recibo. 
En estos recitales suelo tener varios elementos con los que voy interactuando. Con dos ordenadores portátiles coordino las bases musicales, las capas visuales y los efectos generales de sonido. Esto permite variar en directo algunas cuestiones, encadenar una música con otra, modificar pistas, y, simultáneamente, introducir instrumentos en directo sobre las bases pregrabadas. Utilizo dos sintetizadores, un teclado y un panel táctil para producir diversos sonidos. También tengo en todo momento un control exhaustivo sobre la voz, pudiendo manejar en cualquier momento diversos efectos, ecualizaciones, etc.

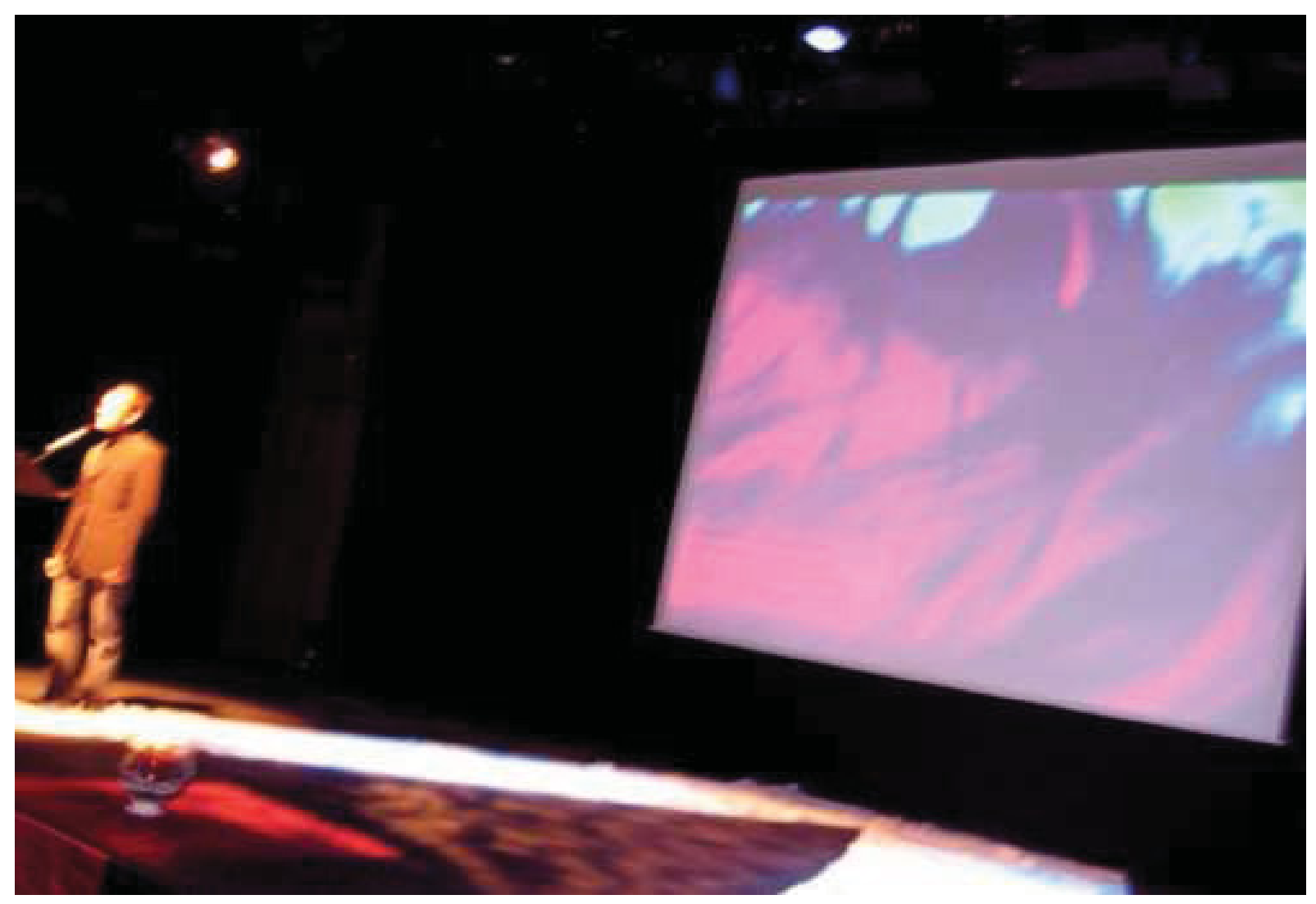

Texto Digital, Florianópolis, v. 7, n. 1, jan./jun. 2011. ISSNe: 1807-9288 
En el terreno visual hay menos improvisación, pero, en algunos casos, he utilizado mezcladores de vídeo para disparar diferentes capas durante el transcurso del recital. Aún así las visuales tienen menos variaciones que la música, centrando la experimentación en directo en el apartado escénico y sonoro.

\section{Del libro a la creación multimedia}

Un libro es estático, un recital es dinámico. El texto pone la base. El recital es la puesta en escena, la ópera, la canción. He hablado mucho sobre la importancia de la oralidad. Si decidí empezar a trabajar en el ámbito de la creación multimedia, es por la necesidad de llevar la literatura a los demás de una forma distinta. No se trata de recitar unos versos, se trata de convertirlos en emoción orgánica. De hacerlos llamarada visual para todos los espectadores.

Esta voluntad de sumergirse en la literatura era la base de la oralidad, de los poetas que siglos antes de Gutemberg hacían disfrutar a los demás con la seducción de la palabra. Ahora las herramientas de la oralidad se están renovando. Disponemos de los medios, de la imaginación, de la creatividad. Sería absurdo no aprovecharlo.

En mi caso personal todos los libros que he publicado han salido en papel. He tenido la suerte de recibir varios premios nacionales e internacionales que me han permitido llevar mi creación literaria a las librerías. Pero siempre aviso de una cuestión importante. Esos libros son el libretto, la letra de una canción que es mucho más amplia. Por supuesto lo puedes disfrutar de forma autónoma, pero la intención creativa del poeta sólo puede verse en la obra completa. Lo comparo a escuchar una ópera sin verla, o a leer la letra de las canciones de un grupo sin escuchar su música. Puede ser interesante, pero no te entregará la experiencia de ver al poeta en directo con su música en vivo, con la secuencias sonoras, con las visuales sincronizadas junto con la declamación. Todos y cada uno de esos elementos elevan el texto, le dan una nueva entidad, y lo entregan a los demás de una forma candente que no nos permite la página escrita. 
De la misma forma, y aunque se pueden ver los vídeos de algunas de mis creaciones en la red, tampoco considero que su visionado pueda dar en absoluto la experiencia completa de la propuesta multimedia. Hay una cuestión que se pierde por completo cuando simplemente ves un vídeo: la escena. Además, todas esas creaciones no están pensadas para ser vistas de forma autónoma, sino para formar parte del recital poético.

\section{Hacia la estética de lo inmaterial}

Considero que cada uno de mis libros lleva un tempo. Tiene una sensación dominante y esa sensación es un ritmo, una música, unos colores y una texturas. El río de impresiones que provoca la poesía, se mezcla con toda una serie de referencias que tenemos dentro de nosotros. Hay determinados colores que significan, que expresan, hay imágenes que nos conmueven con sólo verlas. Y no lo hacen por lo que puedan entregarnos, sino por lo que arrastran dentro de nosotros. Por eso es relativamente sencillo distinguir por la música los textos de mis libros. La música de Espejos enfrentados no tiene nada que ver con la música de Las cántigas del diablo. Que tampoco se parece a Sucio tango del alma, y que dista mucho de Circe. Acumulación de elementos artísticos

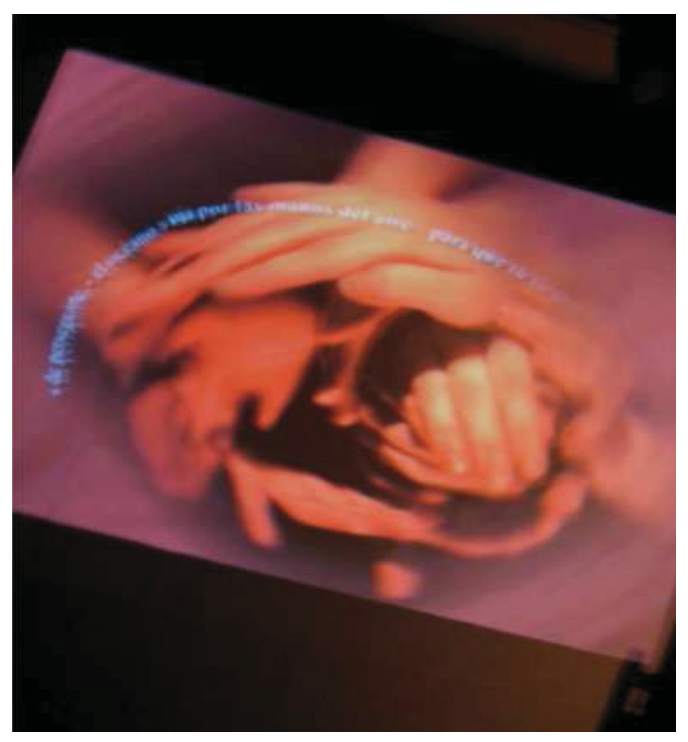
que buscan en el interior el laberinto que tejen los versos.

Antes de publicar mis libros estuve trabajando sobre diversos experimentos utilizando los nuevos medios. Comencé en 1995 con la realización de una serie de proyectos donde se unía la tecnología de esa época, espacialmente en el terreno musical, con la lectura de los versos. Utilizaba sintetizadores y samplers, además de instrumentos tradicionales, componiendo música para cada uno de los textos que utilizaba. De esta manera pude comenzar a desarrollar las propuestas que estoy presentando ahora, pero no tenía aún la posibilidad de trabajar de una 
forma efectiva con el terreno visual. En ese momento comencé a utilizar diapositivas y vídeo en VHS que debía sincronizarse de forma manual, con lo cual podía trabajar sobre texturas, pero no sobre una creación perfectamente integrada en el desarrollo de la música y de la palabra. Unos años después pude empezar a trabajar la parte visual de la forma en que deseaba hacerlo, mediante la integración de la que he hablado en este artículo. El hecho de que pudiera utilizar equipos para la edición de vídeo, para animación 3D y para sincronizar de forma clara la expresión musical con la visual, fue absolutamente decisivo a la hora de desarrollar una teoría poética personal para los nuevos medios.

\section{Espejos enfrentados}

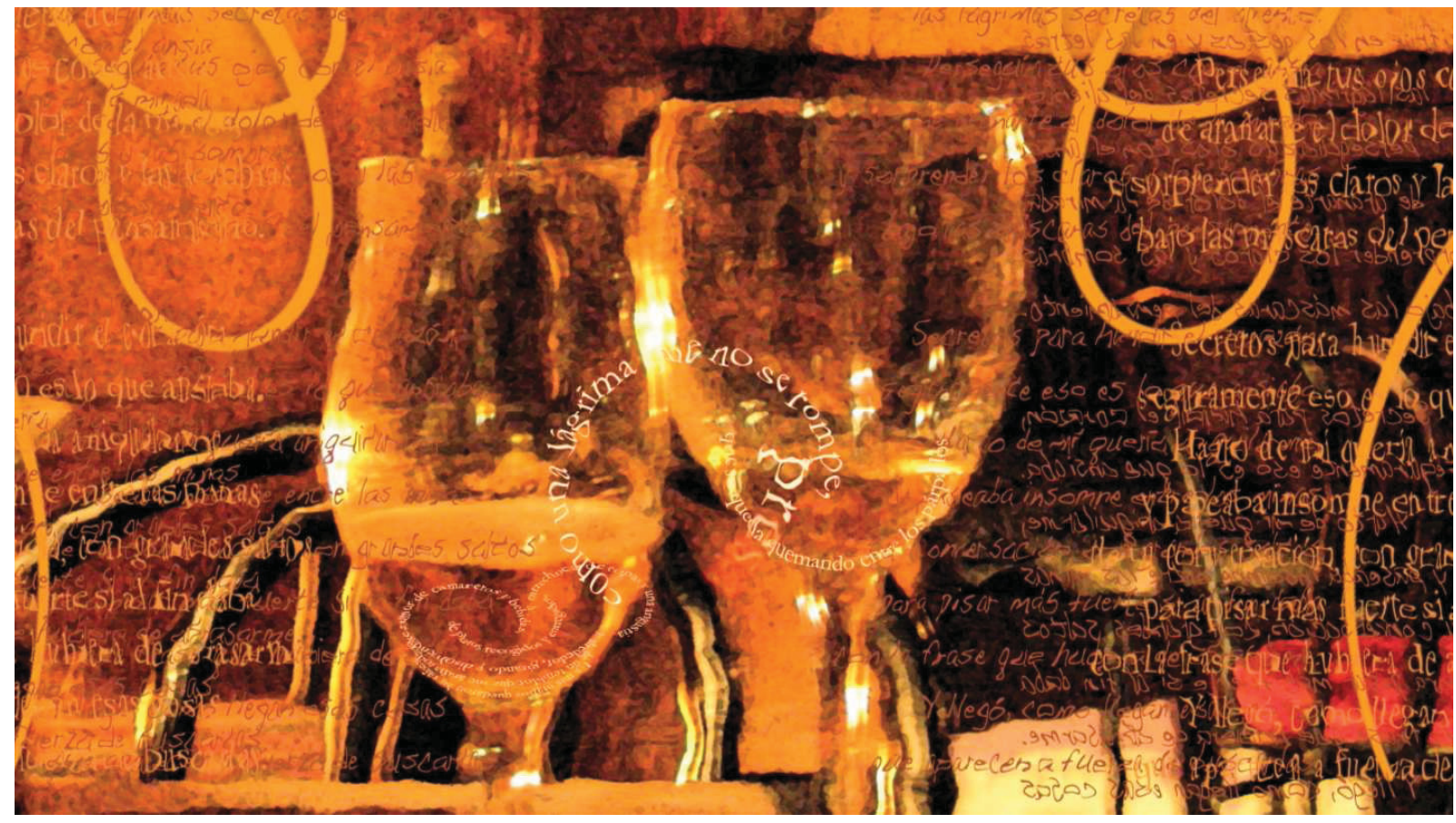




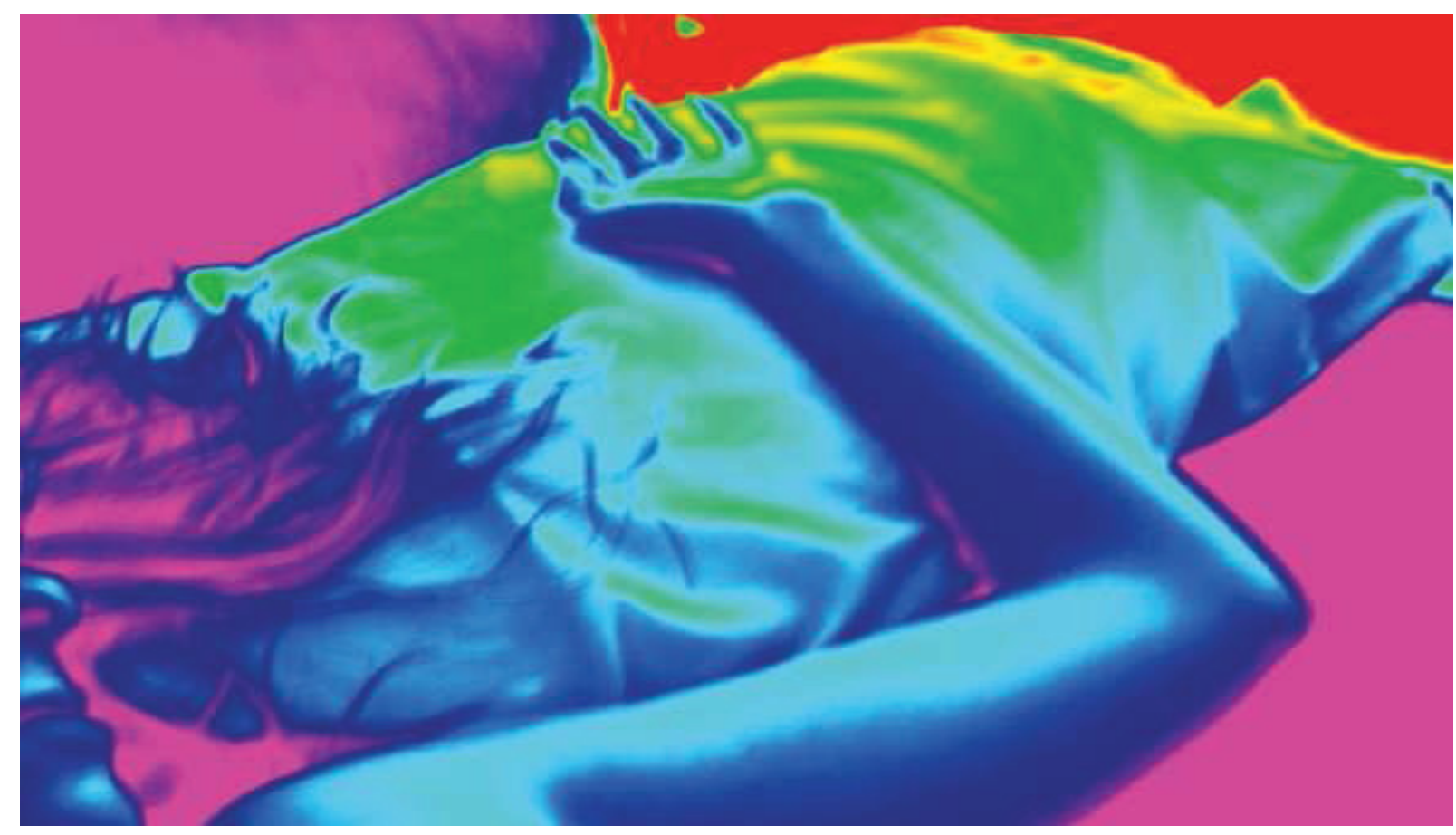

Este libro recibió el Premio Internacional Florentino Pérez-Embid. Fue publicado por la editorial Rialp, en la colección Adonais, y ese mismo año comencé a desarrollar una serie de recitales donde reunía el trabajo que ya había avanzado hasta entonces. A lo largo de esos recitales comencé a hablar sobre la importancia de que cada uno de los textos fuera entendido en relación con el resto de las propuestas artísticas. Sin renegar de la importancia del poema sí comencé a cuestionar la absoluta hegemonía del libro. Los recitales que llevé a cabo durante ese año no estuvieron exentos de controversia. Y, posiblemente, si no hubiera tenido la suerte de llevar un libro premiado conmigo, habría sido imposible que la propuesta se tomara en cuenta en determinados circuitos. En muchos de esos recitales la reacción era encontrada. No existía duda sobre que la propuesta funcionaba, pero sí se cuestionaba si aquello era un recital de poesía u otra cosa distinta.

La diferencia que puede observarse entre esa creación y los poemas que vinieron después es el tempo que comentaba antes. Es un libro para ser recitado despacio, hace de la levedad música de melancolía blanca. Por eso los pianos, las cajas de música, las percusiones 
jazzísticas en los poemas más narrativos. Por eso las texturas visuales sucediéndose de forma lenta, con paletas de color afines, con destellos que se van perdiendo en busca de una memoria en disolución.

Las cántigas del diablo, fue mi segundo libro. Recibió el Premio Nacional Nicolás del Hierro y fue publicado por el Ayuntamiento de Piedrabuena y la Junta de Castilla la Mancha. Son poemas rápidos, concretos, con imágenes donde el incendio, el cambio y la rebelión forman

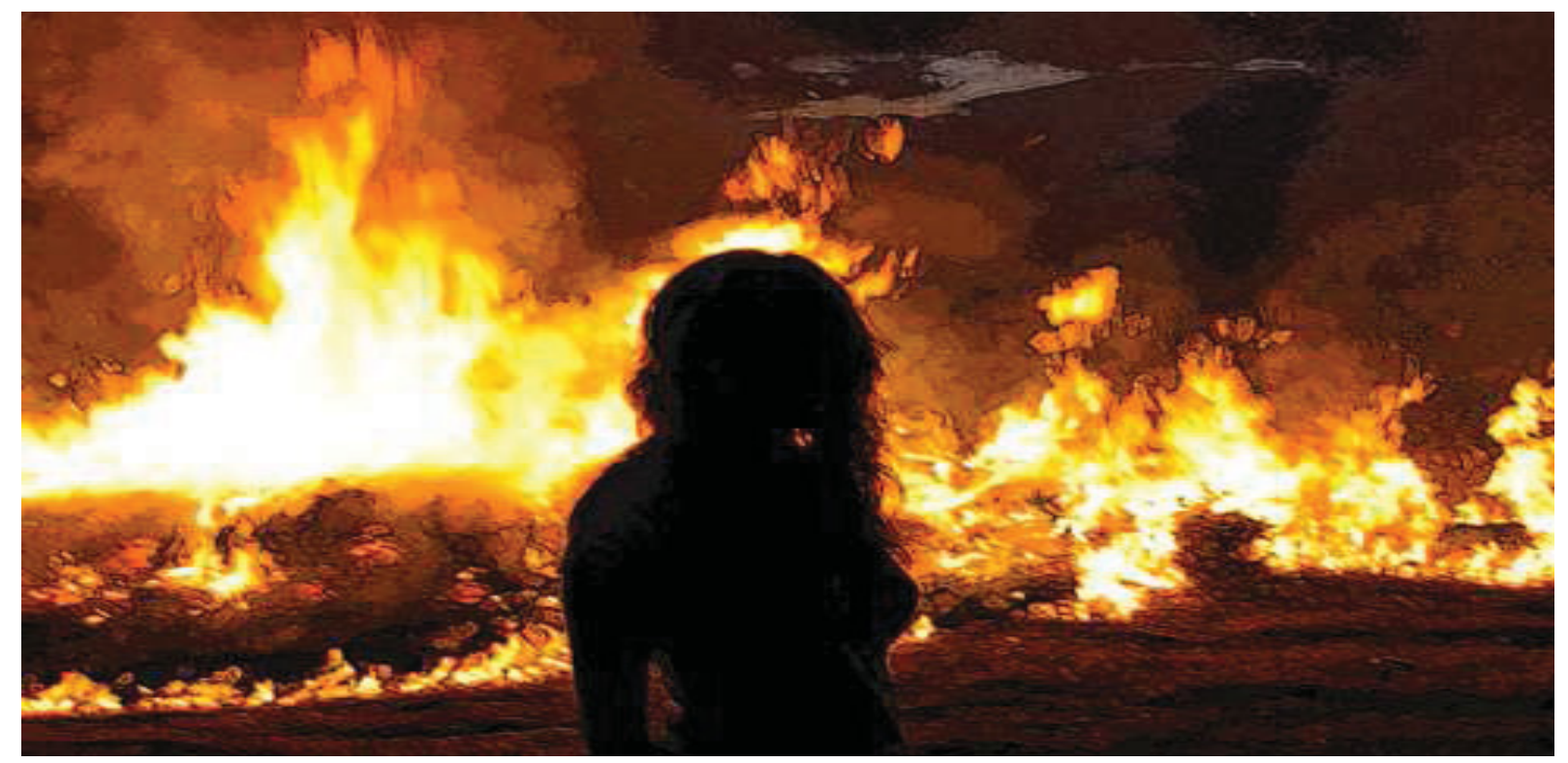

parte del simbolismo que lo alimenta. La música es muy diferente a la de Espejos enfrentados. Percusiones, sonidos electrónicos y sobre todo un recitado rápido, desafiante, que impone una serie de texturas visuales impregnadas de velocidad, de vértigo, de entusiasmo. Tipografías en movimiento, oscilaciones de fuego, vídeos donde se superpone el deseo sobre una llamarada que no quiere extinguirse. También hay en algunas de estas visuales un interés por la poesía visual y por el trabajo conceptual con texto. En algunos casos incluyendo símbolos sencillos que no forman parte del poema, pero sí de su intención. Es el caso del poema "Somos", donde se reúne, de forma acumulativa, toda una serie de palabras que empiezan y acaban por $\mathrm{O}$, utilizando la imagen del círculo asociada a la eternidad, y que 


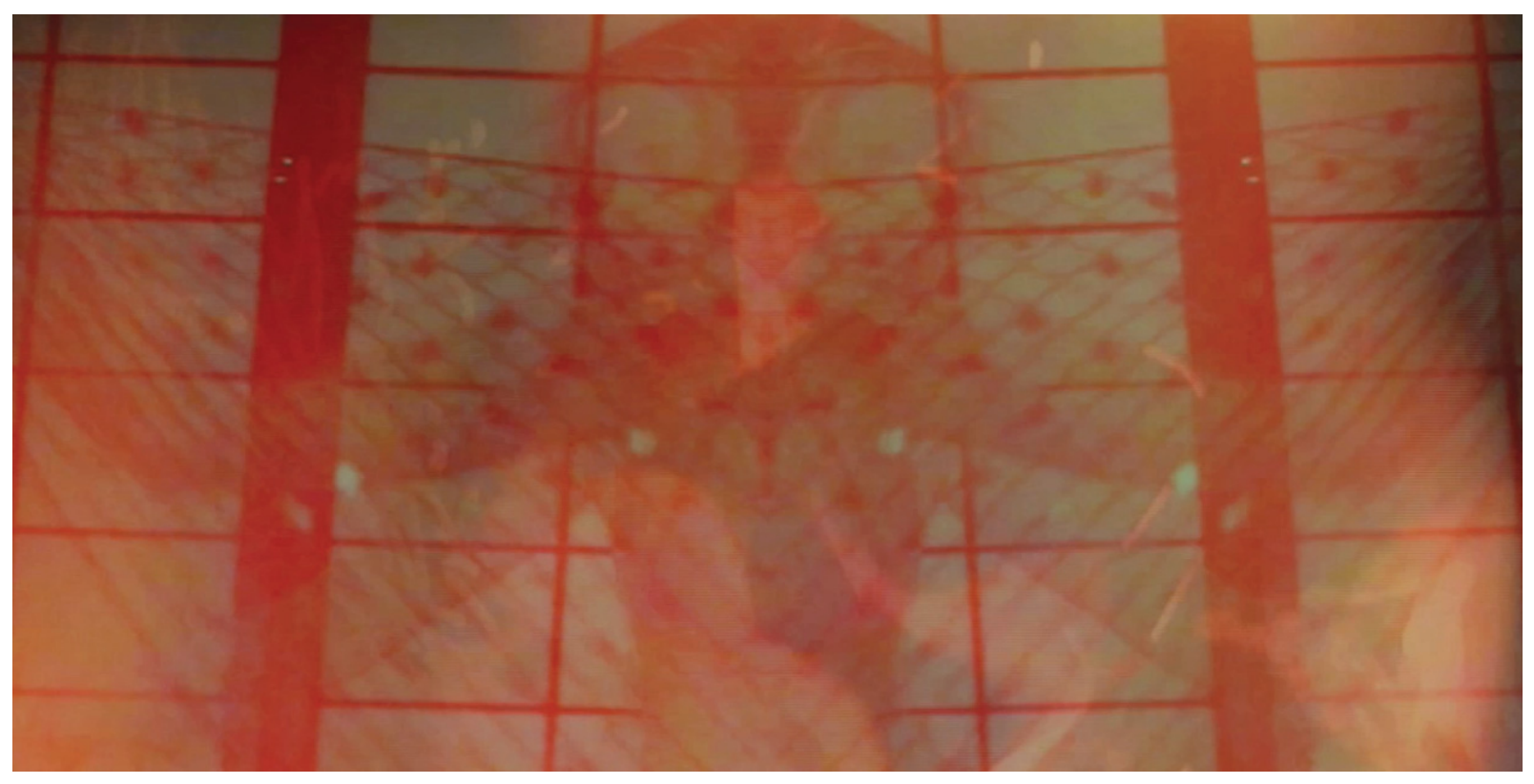

posteriormente se transforman en 8 (símbolo del infinito) Espacio y tiempo bajo el temblor del ser. Bajo la fusión vertiginosa del entusiasmo.

Sucio tango del alma, mi tercer libro, recibió el Premio Internacional Paul Beckett y fue publicado por la Fundación Valparaíso. Este poemario tiene un tono melancólico, pero las imágenes están en otro ámbito diferente a Espejos enfrentados. El recuerdo se llena de humo, de bares, de música de tango. El dolor fuma y maldice y parece buscar la redención cantando. La música tiene unas texturas más densas, casi bailables. Las visuales mezclan la tipografía, el fuego, el humo. Imágenes en blanco y negro en lenta disolución.

Circe es de momento mi último libro. Recibió el Premio Internacional Antonio Gala y fue publicado en la editorial Alhulia. Este texto es una mezcla donde el erotismo, el heroísmo y la omnipresente presencia de la mitología griega pugnan con la decepción, buscando todas las posibilidades para el cambio. Siguiendo la estela de Las cántigas del diablo, vuelve a ser importante la acción. La lucha. Las visuales se sumergen en una tipografía rápida, mezclándonse con texturas que dan una impresión de irrealidad. Mezcla de pasado y futuro, de realidad y referencias míticas en unas visuales donde la mirada de Circe señala, silencia y alimenta el deseo que empuja la sangre. La música tiene un acelerado contenido emocional, con texturas de complejas instrumentaciones étnicas y electrónicas. 


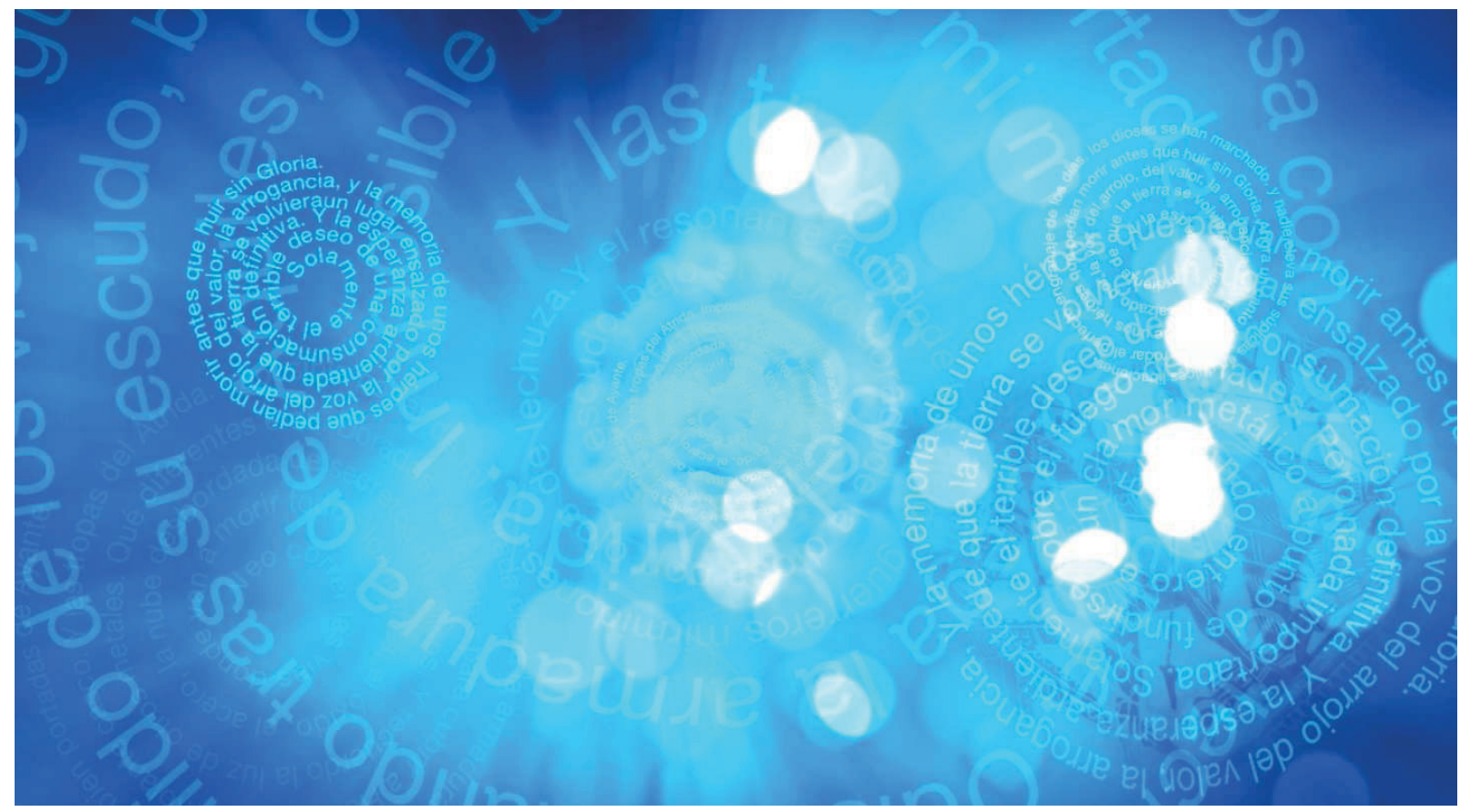

Lo que es común a todos los libros, y a todos los trabajos que he realizado en el ámbito de la literatura multimedia, es el objetivo. Una intención clara de desarrollar todas las posibilidades de la tecnología en favor de la palabra oral. Y para hacerlo la música, las visuales, y la experimentación electrónica se funden impulsando la creación de una nueva obra sobre los cimientos del verso. 